\title{
A quantitative study of Prince Albert's crime/risk reduction approach to community safety
}

\author{
Murray J. Sawatsky, Rick Ruddell, ${ }^{*}$ and Nicholas A. Jones*
}

\begin{abstract}
Faced with escalating crime rates and increasing demands for services, the Prince Albert Police Service led a mobilization effort to implement a crime/risk reduction strategy called Community Mobilization Prince Albert (CMPA). This study examines the evolution of crime prevention practices from traditional police-based practices that rely on focused enforcement practices, to the emerging risk reduction model, wherein police-led partnerships with community agencies are developing responses to the unmet needs of individuals and families facing acutely elevated risk (AER). These community mobilization strategies have resonated with justice system stakeholders throughout Canada, diffusing throughout the nation in a relatively short period of time. This study examines the outcomes of these crime prevention efforts and their results on reducing crime and social disorder and the associated costs of crime to society, after implementation of CMPA in 2011. In order to evaluate the crime reduction efficacy of this approach, crime rates and the costs of crime were examined prior to the adoption of the mobilization efforts and afterwards. We find a statistically significant decrease in the rates of violent and property crimes after the introduction of the community mobilization approach, and the costs to society of these offences also decreased. Given those findings, a number of implications for policy, practice, and future research are identified.
\end{abstract}

Key Words Community mobilization; crime reduction; proactive policing; costs of crime; police calls for service; acutely elevated risk.

Journal of CSWB. 2017 Mar;2(1):3-12

www.journalcswb.ca

\section{INTRODUCTION}

This research examines the outcomes of a community mobilization model that was developed to reduce levels of crime and social disorder in Prince Albert, a community of 45,182 residents situated in rural Saskatchewan (eHealth Saskatchewan, 2015, p. 117). This approach, formally introduced in 2011, emerged as a partnership between the Prince Albert Police Service (PAPS) and a number of local stakeholder groups, including representatives from health, education, and social service agencies. The community mobilization approach was developed after a realization that the police, by themselves, could not manage the growing demands for service and escalating crime. This led the PAPS administration to both examine its internal operations, as well as conduct a global search for promising crime reduction practices.

As part of their operational review, the PAPS tracked its calls for service (e.g., 911 calls) and estimated that, with the growing public demand year over year coupled with increasing crime rates, the police service would have to continue to hire more police officers. Chief Dale McFee stated that he could not hire enough police officers to keep up with the escalating demand for service, although also acknowledging that many calls for service were in response to social problems and not directly related to crime (McFee \& Taylor, 2014).

In addition to their operational review, the PAPS administration and stakeholders examined programs from around the globe in search of solutions. These stakeholders focused their attention upon Community Safety Glasgow (CSG), a Scottish crime-reduction program developed in response to high rates of crime and violence in marginalized populations (EKOS Ltd., 2011). Despite the demographic differences in the populations in Glasgow and Prince Albert, there was a parallel series of social problems in the two places, including high levels of antisocial behaviour, substance abuse, community dysfunction, and crime (McCluskey, 2013). Anecdotal accounts of the CSG approach revealed that it was a promising crime reduction effect and some elements of that model were used in the development of the CMPA. Although Canadian police services have engaged in partnerships with community agencies in the past, the CMPA approach is a more formalized and long-term approach. The CMPA partners also step more aggressively into involvement with individuals and families in situations of elevated risk by intervening early and providing a full range of services to meet their unmet needs (Nilson, 2015; 2016). 
Focusing crime prevention and reduction efforts on at-risk individuals shifts the paradigm of the police from reactive suppression efforts to one of identifying at-risk individuals early so targeted and purposeful interventions can prevent recidivism and, perhaps, even preventing individuals from offending in the first instance. If this approach is successful, future crime prevention programs might be designed to identify and address risky behaviours in at-risk individuals and families, as opposed to responding to offenders in a purely reactive manner. A reduction in criminality results in less crime and victimization, and all of the direct and indirect costs associated with victimization (Easton, Furness, \& Brantingham, 2014).

\section{Research Questions}

After reviewing the extant literature on policing and community-based mobilization models, the following two research questions were developed:

1. What was the impact of the 2011 introduction of the CMPA on the police-reported crime rates (e.g., specific offences such as break, enter, and theft); and,

2. Did the introduction of the CMPA reduce the costs of crime in Prince Albert?

Answering these questions will shed light on the efficacy of community mobilization approaches to reducing crime and social disorder, and the economic benefits of those efforts.

If community mobilization approaches are indeed effective, the positive impacts for policing and community social service agencies would be considerable. Although the core functions of the police to investigate and respond to crime would remain, more resources could be dedicated to working in concert with other agencies in the identification of at-risk individuals and appropriate interventions carried out. Early analysis of changes in the overall crime rates and calls for service in Prince Albert shows promise that this approach may, in fact, lead to crime reduction (Nilson, 2014). This research examines the CMPA approach to community safety and crime reduction to determine whether this approach is: quantifiably, a successful crime reduction strategy, and of economic benefit to society. In what follows, we describe the crime problem and social disorder situation in Prince Albert, provide a brief overview of the CMPA model, and describe the data and methods used in this study. We also discuss the implications of the research findings and how they can inform policy, practice, and future empirical work.

\section{Crime and Social Disorder in Prince Albert}

In order to better understand the situation in Prince Albert that led to the development of the CMPA it is necessary to provide an overview of the conditions within the community, with a specific focus on the geographical and demographic characteristics of the city, followed by a description of the crime and social disorder challenges as they existed in the years leading up to the development of the community mobilization model. There are, for example, a number of factors that make the community of Prince Albert distinctive. The city is situated near the centre of the province and because of its geographical location is often referred to as a "gateway" to the north. Because of its status as a gateway city, there is a large transient population passing through the community on any given day for shopping, recreation, and family visiting, and this churning population contributes to social disorder and a distinctive pattern of crime. Many of the northern communities that "feed" into Prince Albert have very high levels of police-reported property and violent crime (see Allen \& Perreault, 2015). Table I shows the overall crime severity index (CSI) for seven surrounding communities within a three- or four-hour drive of Prince Albert (Statistics Canada, 2016). One of the shortcomings of our knowledge, however, is that we do not know the actual contributions of residents from these communities to Prince Albert crime rates, and we are only speculating that these visitors engage in crime in this community at rates similar to their home communities (Table I).

Prince Albert is characterized with high rates of unemployment, school failure, single parent households, and poverty (Fenno, 2013). Moreover, the community population has a large and rapidly growing population of young persons aged 15 to 24 years. Altogether, these community conditions lend themselves to a high degree of social disorganization (Ha \& Andresen, 2017). Social disorganization is associated with a range of addictions and crime-related problems. Alcohol and drug abuse, for example, is an entrenched community problem and over one million syringes were distributed in this city as part of a needle exchange and recovery program in 2014 alone (Pilon, 2015). With respect to young persons, Fenno (2016) found that rates of youth substance abuse in PA high school students were several times the provincial and national averages. Hamilton (2016) links substance abuse and health-related problems, such as the spread of sexually transmitted infections; rates of new HIV cases in Prince Albert are 3.5 times the national average (Leo, 2015). Altogether, the community is characterized by high rates of social disorganization and low levels of collective efficacy. High levels of substance abuse, transient populations, and social disorganization are associated with antisocial behaviour and crime, and crime rates in Prince Albert are more than three times greater than the Canadian average.

With respect to crime, McFee and Taylor (2014) found that the number of arrests between 1999 and 2008 increased by $128 \%$ and this trend was projected to continue, despite the fact the city's population remained relatively stable. Calls for service for the years 2007, 2008, and 2009, for example, saw overall

TABLE I Communities that "feed into" Prince Albert: overall crime severity (2010 and 2015) ${ }^{a}$

\begin{tabular}{lccc}
\hline \multicolumn{1}{c}{ Place } & $\begin{array}{c}\text { Kilometres from } \\
\text { Prince Albert }\end{array}$ & $\begin{array}{c}\text { 2010 CSI } \\
\text { (Overall) }\end{array}$ & $\begin{array}{c}\text { 2015 CSI } \\
\text { (Overall) }\end{array}$ \\
\hline Waskesiu & 90 & 633 & 689 \\
Big River & 132 & 259 & 272 \\
La Ronge & 241 & 554 & 508 \\
Beauval & 311 & 432 & 385 \\
Deschambault Lake & 323 & 523 & 514 \\
Pierceland & 364 & 251 & 308 \\
\hline Pelican Narrows & 386 & 908 & 805 \\
\hline
\end{tabular}

a The crime severity index is an indicator of the volume and seriousness of crimes reported to the police (see Statistics Canada, 2009 for a description) 
increases of $2.5 \%, 4.5 \%$, and $6.2 \%$, respectively, although the population remained relatively stable during those years. The reality of the impact on service providers in the city was demand for services that would be consistent with cities with a population of 60,000 rather than 40,000 residents (McFee \& Taylor, 2014). In 2010 - the year prior to the full implementation of the CMPA-Prince Albert scored 260 on the Violent Crime Severity Index (V/CSI) and 221 on the overall Crime Severity Index (CSI), compared to Saskatchewan V/CSI value of 153 and 148 for the CSI (Statistics Canada, 2016). These totals were much higher than the national average of 88 (overall CSI) and 94 (violent CSI).

The growing number of police calls for service in Prince Albert and the increasing seriousness of these offences were beginning to overwhelm the conventional police and community responses to these occurrences. Yet, not all calls to the police are related to crime and the PAPS (2008) determined that only $24 \%$ of calls to the police actually required a police response; the other $76 \%$ were categorized as social disorder type calls. Skogan (2012) states disorder ranges from that which is clearly criminal to behaviour that may simply be an annoyance. In other words, although the police may have responded, the underlying causes of the issue may have been one of addictions due to drug or alcohol abuse, relationship issues or some other problem that could be handled better by staff members working in a social service agency, by community-based agencies that specialize in specific social problems (e.g., family dysfunction), or by addiction services provided through health agencies.

High levels of antisocial behaviour and crime can have a corrosive impact upon a community's educational, health, and social service systems. For example, Prince Albert students were having problems with truancy and difficulties adjusting to school. Furthermore, the local emergency room was dealing with a growing number of injuries related to substance abuse and assaults, and an increasing number of children were being apprehended from their families by social service agencies (Nilson, 2014).

Altogether, the demands for health and addiction services, social services, and policing in Prince Albert showed no signs of ending. In a report prepared for the Deputy Minister of Corrections, Public Safety and Policing, Taylor (2010) describes a number of indicators of the province's wellness, crime severity and fear of crime. He advises that a large proportion of crimes can be associated with the province's growing "at-risk" marginalized Aboriginal population, and observes that:

The staggering economic, health, education and substance abuse statistics in aboriginal Communities, especially in the more remote areas of the province quite obviously place a significant number of the province's residents at risk among the standard determinants of criminality. These same factors render others highly vulnerable to victimization, especially, aboriginal women. Many of these same prevailing conditions and risk factors are widely out of step with similar indicators across the province's non-aboriginal population... While overall crime severity rates are generally decreasing across Canada and Saskatchewan, crime severity indicators in Regina, Saskatoon and Prince Albert reflect increasingly violent behaviour among young offenders and a continued and dramatic rise in arrests related to intoxication and substance abuse... For example, of total persons arrested in Prince Albert last year, almost 40\% were not residents of the city (pp. 11-13).

As noted by Taylor, with the reality of this growing at-risk population, faced with increasingly unsustainable demands on resources, the community of Prince Albert was facing a crisis.

\section{What is the Community Mobilization Prince Albert (CMPA) Model?}

CMPA is an integrated multi-agency committee that has a goal of building safer and healthier communities by enhancing the delivery and responsiveness of human service agencies. The goal of these interventions is to target at-risk individuals and families with the greatest number of unmet needs. That goal is accomplished by mobilizing community resources to address cases with elevated levels of risk as recognized and identified by service providers. Although reducing risk is one goal, CMPA also has a broader focus on creating a healthier community over the long term.

In the business case for the establishment of CMPA to the Saskatchewan Ministry of Corrections, Public Safety and Policing in early 2010, it was reported that alternatives in Prince Albert were being explored, including coordinated multi-agency responses. Skogan (2012) observes that, "Disorder independently but always in tandem with other conventional crime, plays a role in determining the stability of urban neighbourhoods, undercutting natural processes of informal social control, discouraging investment, and stimulating fear of crime" (p. 187). When informal social control breaks down, there is a corresponding need for more formal social control, such as the police responding to restore order (Skogan, 2012). Through the active involvement of the partners the highest risk cases are identified and provided with interventions and services that are designed to reduce their risk.

More broadly, over the long-term, the CMPA business plan predicts seven key community benefits will result from the multi-agency work. According to Nilson (2014, p. 30) those seven benefits include:

i. diverse resources focused on the issue at hand;

ii. protective and efficient service delivery;

iii. better follow-up directed towards long-term change;

iv. enhanced frontline working relationships between agencies;

v. service delivery that is focused on problems and not on ownership of the problems;

vi. information- and expertise-sharing geared towards long-term system needs; and,

vii. modelling emerging trends on a variety of evidencebased models in crime reduction and overall community safety and wellness.

\section{The CMPA Hub}

The first element of the CMPA model is the Hub, which became the forum around which all participants could hold discussions regarding individuals who came to the attention of agency staff due to their involvement in risky, destructive 
or otherwise unhealthy situations. Examples might include a youth engaged in substance abuse, a family with children out of parental control, or incidents of family violence. The Hub holds discussions amongst agencies in the human services sector and meets to discuss and address situations of acutely elevated risk. According to Nilson (2014, p. 44), acutely elevated risk is defined by CMPA as (a) significant interest at stake; (b) probability of harm occurring; (c) severe intensity of harm; and (d) multi-disciplinary nature of elevated risk.

The Hub meets for one to two hours twice weekly. This group does not have any actual case management role or authority, but rather meets to problem-solve and discuss cases that have come to the attention of any participating agency. The case management and the actual service delivery responsibility remain with the appropriate agency or group of agencies. The focus of these meetings is to identify individuals or families whose risk cannot be minimized by any one agency, acting alone. Any of the participating agencies may identify a risk situation that has come to its attention. As each situation is discussed amongst the member agencies, the most appropriate human services are identified and staff members from those agencies become engaged in a planned intervention to mitigate the situation. After identifying the agencies responsible for the intervention, it is up to them to refine their plan, determine the most appropriate time to stage an intervention, and report back to the group on the outcomes of their efforts. The goal of the Hub participants is to stage an intervention within 24 to 48 hours of the matter being brought to their attention (Nilson, 2014). As of January 15, 2015, the following agencies participated in the Hub:

Saskatchewan Social Services (e.g., child protection and income assistance),

- Prince Albert Parkland Health Region (e.g., mental health, addiction services, public health, acute care, patient care),

- Prince Albert Police Service (policing, bylaw and victim services),

Prince Albert Roman Catholic Separate School Division, Saskatchewan Rivers Public School Division,

- Prince Albert Grand Council, a federation of 12 First Nations,

Royal Canadian Mounted Police,

Mobile Crisis, an agency that responds to family and community emergencies after regular business hours, and;

- Ministry of Justice - Corrections and Policing (adult and youth probation and policing services).

The agency membership at the PA Hub has expanded since its formal inception in February 2011, but it is limited to the attendance of organizations that most frequently contribute to resolving the issues raised by the Hub situations.

The Hub is not intended to be a forum for discussion of any or all situations where individuals or communities may require some form of help or assistance from human service providers. Rather, it is a discussion reserved for situations requiring a coordinated response before a situation deteriorates and requires a traditional and often punitive response from the formal justice system (e.g., providing supports to a case of family dysfunction before the circumstances escalate into violence).
Actions as a result of a Hub discussion are typically undertaken by one or more agencies working together to offer services. The offer of services often involves a visit to an individual or family deemed to be in need of assistance. Representatives from the agency(s) involved offer to provide a service and, if accepted, the services are delivered by the individual agencies as part of the mandates of those organization(s). This approach is thought to increase interagency cooperation and more effective integration of services.

Nilson (2014) reports that between February 2011 and May 2014 about 600 cases were reviewed by the Hub. The 2012 CMPA report on the Hub discussion provides a one-year (June 1, 2011-May 31, 2012) analysis of 258 situations brought before the Hub for formal discussion, and notes that most of them required more than one discussion, averaging 5.6 discussions per situation and the average time for each discussion was about 6.5 minutes. As a result of the Hub discussion 694 tasks were defined, assigned, and carried out by the agencies, often in a cooperative manner. Twelve per cent of the situations were viewed by the committee as chronic and required the highest intensity of service.

According to the CMPA (2012), almost three-quarters (71\%) of the situations were brought to the Hub discussion table by one of three agencies: social services (19\%), education (21\%), and the PAPS (31\%). Fourteen per cent of the situations discussed required intervention from health services. Of the situations brought forward for discussion, child-related issues comprised $37 \%$ of the cases, while addictions accounted for $20 \%$ and mental health services $60 \%$. The top risk factor that led to interventions was substance abuse $(57 \%)$, which was followed by criminality (56\%), victimization (41\%), mental health issues $(30 \%)$, missing person cases $(28 \%)$, parenting issues (19\%), and truancy (14\%). With respect to the effectiveness of these interventions, the CMPA (2012) reports that:

The range of positive effects of the Hub discussion was found to be wide. The results often would not have been obtainable to the same extent without the collaborative approach. The Hub mitigated acutely elevated risk situations to the benefit of the individual, his/her family, and the community at large. It increased community safety and wellness, the effectiveness, efficiency, and quality of our human services delivery system by mobilizing existing resources, enabling service delivery, and making it take place at an earlier point in time. Also, it allowed for the identification of systemic issues and gaps (pp. 2-3).

While the Hub represents the operational aspect of community mobilization, the CMPA also has a long-term orientation that is intended to respond to the root causes of antisocial behaviour, social disorder, and crime.

\section{The Centre of Responsibility (COR)}

While the Hub focuses on rapid response and short-term issues affecting individuals and families, the COR is a fulltime dedicated operation with a mandate to resolve longerterm systemic solutions to community dysfunction, including responding to disorder and crime. The COR's focus is on the broader notion of community safety and wellness, while seeking longer-term community goals and initiatives that are guided by research and analysis. 
In addition to specialized analysts, the COR is staffed by a group of human service professionals who are seconded away from their regular agency positions on a temporary basis to work in this collaborative environment. The COR engages in outreach by providing learning and information sharing opportunities to government leaders, human service professionals and other interested parties about CMPA and its efforts to increase community well-being and reduce crime. COR staff members also collect and analyze data, and evaluate the efficacy of CMPA by measuring the outcomes associated with the program. The COR is also responsible to research community engagement and communication with the HUB participants to identify systemic problems.

Welch and Farrington (2010) describe developmental and situational crime prevention in terms of three categories of prevention and intervention: primary, secondary, and tertiary. Primary prevention focuses on the well-being of all individuals in the community. Secondary prevention involves interventions with individuals or families who are at risk of offending, while tertiary prevention involves measures to deal with offenders and victims (Welch \& Farmington, 2010, p. 2). The CMPA model engages all of the agencies mandated to carry out these three intervention approaches. The COR advocates for primary prevention through the development of holistic programs that promote community well-being. Secondary and tertiary prevention, by contrast, are undertaken by the Hub, as it intervenes and provides services to at-risk families and individuals, as well as those who have become involved with youth or adult justice systems as offenders or victims. Although the Hub does respond to offenders and victims, the goal of the CMPA is to intervene before crimes occur.

\section{Literature Review}

The thesis from which this paper was summarized includes a comprehensive review of the relevant literature. Among other theoretical models, it examined Crime Prevention Through Social Development (CPTSD) and how the theory of social disorganization can help us understand the conditions of crime and disorder present in Prince Albert. Traditional and innovative approaches to policing were also examined, along with the legislated responsibility for the police in the prevention of crime. This literature review showed that policing has evolved in response to limitations in traditional models of policing to reduce crime. Since the 1980s there has been increased attention on researching and evaluating evidence-based or best practices in policing (Lum, Koper \& Telep, 2011). There are a growing number of crime reduction strategies that have been implemented and refined by using this approach. However, in general there is growing awareness that the police cannot "go it alone" and require the support of other community agencies. Some communities, such as Prince Albert, have both high proportions of marginalized populations and conditions of deprivation, including unemployment and poverty.

Research also shows that undirected enforcement efforts cannot bring about meaningful reductions in crime (Aos \& Drake, 2013). Rather a community mobilization approach that recognizes enforcement must be combined with other evidence-based approaches to reduce risk factors in order to reduce offending. Although there is not an overwhelming body of research supporting approaches such as CMPA, there is an emerging literature suggesting that crime reduction is best achieved through partnerships where the key goal is one of reducing risk. Similar to the research carried out by Griffiths and colleagues (2007), Bottoms (2006) speculates that early intervention in the lives of youth at-risk results in crime reduction by changing their pro-criminal behaviours and attitudes. The United Nations Office on Drugs and Crime (2010) also identify a similar set of factors that are associated with crime and violence such as: pro-criminal values, thoughts, beliefs, as well as social factors such as poverty, poor school attendance, and improper parenting.

Altogether, a review of the extant literature shows that, since the 1990s, conventional thinking amongst researchers and practitioners regarding crime reduction approaches has evolved from programs based principally on enforcement to a broader understanding of the social conditions and causal factors that increase the risk for offending. Recent scholarship suggests that changing these underlying factors presents the best opportunity to bring about long-term crime reduction (Jameson, 2008). Making these changes, however, will take time and considerable effort, and they will only be used widely if supported by empirical research.

\section{METHODS \& DATA}

Two strategies were used to carry out this exploratory analysis of the crime reduction effects of the CMPA: (a) an examination of changes in crime rates, and (b) estimating the crime reduction benefits to society. Both analyses were based on monthly crime data collected from the Prince Albert Police Service (PAPS) from January 1, 2006 to June 30, 2015. The indicators used in the analyses reported below included the following classifications of the police-recorded crime rates per 100,000 residents: (a) violent offences such as murder, sexual assault, assaults, robbery, and other crimes against persons; (b) property crimes (e.g., break and enter, motor vehicle theft, fraud); and (c) "other" offences, a category including public order offences, such as wilful damage or impaired driving and administration of justice crimes, such as failure to appear in court.

The study uses a pre- and post-implementation methodology, where the police-reported crime rates are examined 53 months prior to the introduction of the CMPA and 53 months afterward. CMPA became operational in February 2011, and the analyses focus on two timeframes. The first is the 53 months immediately preceding implementation (January 1, 2006 to January 1, 2011) and 53 months following the CMPA's introduction in February 2011 (2011-2015). The second series of analyses excludes six months between February 1, 2011 to July 31, 2011 to account for the fact that the CMPA start-up was an evolutionary process and we shouldn't expect immediate results (e.g., initiating a crime reduction strategy on February 1 and expecting a meaningful change by March 1). Because of the longitudinal nature of the data, $t$-tests were used to examine changes in the average monthly offence rates. This strategy has been used in studies examining the pre- and post-impacts of police worn body cameras (Jennings, Lynch, \& Fridell, 2015) and after the introduction of gunshot detection systems (Choi, Librett, \& Collins, 2014). 


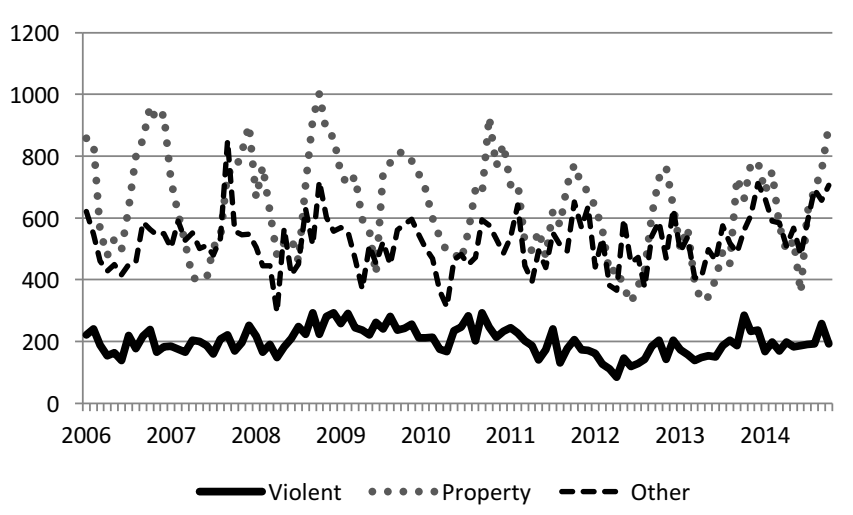

FIGURE 1 Crime trends, Prince Albert, Saskatchewan: January 1, 2006 to June 30, 2015.

Figure 1 shows the actual crime rate trends from 2006 to 2015. Two observations can be made from this figure. First, crime rates do show a subtle downward movement after the CMPA was introduced in February 2012. Second, the Prince Albert crime statistics are seasonal, and property and other offences are much higher in the spring and summer months, and then moderate in the winters. It is plausible that the number of travellers from surrounding communities not only temporarily swells the population, but also contributes to the patterns of higher offending in the summer months. Despite the seasonality, we can observe that the higher "highs" decrease after the CMPA interventions were introduced.

A second series of analyses examined the potential cost savings that could be achieved through crime reduction. A preferred method of evaluating the outcomes in any human service endeavour is to compare the operational costs of implementation contrasted against the benefits to society. Calculating the true costs and benefits of an intervention is a complex undertaking, as it is often difficult to place a price tag on outcomes such as reduced crime (Lee, Aos, \& Pennucci, 2015). Tonry (2015, p. 695) describes the challenges associated with measuring the true costs of crime. He observes that many cost-benefit studies fail to accurately measure the true costs due to incomprehensive factors being measured, an inability to capture social costs, and the true costs of victimization. In this research, the benefits are calculated in terms of crime reduction. The direct and indirect costs of crimes to society have been estimated by a number of U.S. scholars (McCollister, French \& Fang, 2010; Heaton, 2010) and Canadian researchers (Andresen, 2012; Gabor, 2016; Easton, Furness, \& Brantingham, 2014; Zhang, 2011; Zhang, Hoddenbagh, McDonald et al., 2013).

We used Gabor's (2016) estimates of the costs of crime as they were based on the most current research and were developed in Canadian dollars. Gabor developed these estimates after analyzing 65 peer-reviewed and government studies that provided an estimate of the costs of crime and the responses of the justice system to crime. Although most of the studies Gabor considered were from the United States, other nations including Canada, Chile, France, Italy, New Zealand, Poland, and South Africa were also considered. Most (70\%) of the studies Gabor analyzed were based on the "bottom-up" cost-calculation method which is also known as the accounting-based method (for a review of different methodological approaches to estimating the costs of crime see Dominquez \& Raphael, 2015; Heaton, 2010). All of Gabor's estimates are reported in 2014 Canadian dollars.

With respect to methodology, according to Gabor (p. 5), "three measures of central tendency were used to compute the estimated total cost of each crime across the studies"averaging with the outliers removed (as the extreme estimates tended to skew the results), and "calculating the median for each cost category and then adding the results." In order to produce the most conservative analyses, only the two later measures are used: the mean with the outliers removed and the median value for each cost category. As a result, these costs are significantly less than other commonly used research on the costs of crime. McCollister, French and Fang (2010), for example, estimated the cost of a single homicide at \$9,746,213 in 2010 U.S. dollars, while Day, Koegl, Rossman et al. (2015, p. 16) estimated the cost as $\$ 5,962,641$ in 2013 Canadian dollars. In addition to being a more conservative measure, the Gabor figures are more comprehensive and provide estimates for a larger number of crime categories than most other studies. The estimates used in the analyses are shown in Table II.

\section{RESULTS}

Table III presents the descriptive statistics and the results of the $t$-tests examining three categories of crime: violent, property, and other offences per 100,000 Prince Albert residents. Panel one in the table shows the descriptive statistics for the entire 106 months and panels two and three present the descriptive statistics for the pre-implementation (53 months) and post-implementation (53 months) eras. In this series of analyses no cases were excluded. The results of the $t$-tests are presented in panel three and reveal there was a statistically significant reduction after the introduction of CMPA in violent crime $(p=.002)$ and property offences $(p=.011)$. The results for the pre-and post-implementation analyses are also presented excluding all cases from February 1, 2011 to July 31, 2011. These findings show there was a statistically significant reduction in the same two crime categories: violent crime $(p=.000)$ and property crime $(p=.005)$. Neither set of analyses showed a statistically significant reduction in other crimes. Despite the fact that the crime reduction in the post-implementation period showed a statistically significant decrease, the number of crimes that were reduced on a monthly basis were relatively modest.

The second series of analyses considered the cost reductions associated with changes in levels of crime in Prince Albert before and after the CMPA intervention. Using the same monthly crime statistics as reported in Table III, we found the outcomes of these cost analyses are somewhat sensitive to the era being examined. The results, presented in Table IV, show the mean monthly costs of crime increased somewhat when all 106 months were considered, but those costs decreased when the six months between February 1, 2011 and July 31, 2011 were excluded from the analyses (leaving 47 months post-implementation). The second series of analyses show that substantial cost savings were realized to victims and society after the implementation of the CMPA.

There are a number of factors that might drive the results presented in Table IV. Some offences, such as homicide, 
PRINCE ALBERT'S CRIME/RISK REDUCTION APPROACH, Sawatsky et al.

TABLE II Cost of crime estimates, mean and median costs of crime, 2014 Canadian Dollars (Gabor, 2016)

\begin{tabular}{|c|c|c|}
\hline \multicolumn{3}{|c|}{$\begin{array}{l}\text { Gabor (2016) Mean and Median Costs of Crime: } \\
2014 \text { Canadian Dollars }\end{array}$} \\
\hline $\begin{array}{l}\text { Crime } \\
\text { Type }\end{array}$ & $\begin{array}{l}\text { Mean Cost Estimate } \\
\text { (Outliers Removed) }\end{array}$ & $\begin{array}{l}\text { Median Cost } \\
\text { Estimate }\end{array}$ \\
\hline Homicide & $\$ 4,837,018$ & $\$ 5,400,708$ \\
\hline Sexual Assault & $\$ 136,372$ & $\$ 139,347$ \\
\hline Robbery & $\$ 32,002$ & $\$ 28,056$ \\
\hline Assault & $\$ 58,886$ & $\$ 19,075$ \\
\hline Break and Enter & $\$ 5,928$ & $\$ 6,054$ \\
\hline Motor Vehicle Theft & $\$ 8,157$ & $\$ 8,644$ \\
\hline Fraud & $\$ 45,030$ & $\$ 45,030$ \\
\hline
\end{tabular}

rarely occur and reducing these crimes may be due to factors unrelated to the CMPA, such as improved medical care for victims of serious assaults. In addition, the results showed an increase in the number of sexual assaults being reported in Prince Albert after 2011, which increased the costs of crime. That outcome might be a result of survivors of these assaults who have a greater trust and confidence in the police after the implementation of the CPMA and these individuals may be more likely to report these offences. The results from the 2014 GSS victimization survey show that sexual assault is the violent crime least likely to be reported (Perreault, 2015). As a result, the more accurate reporting of some types of offences could drive the results about cost savings even though the actual rate of victimization may have been stable or even decreased during the era examined.

Another factor influencing the results of these analyses is that the costs for a large volume of frequently occurring and relatively minor crimes, such as impaired driving, drug possession, or mischief, were not considered (for a complete list of these offences see Maxwell, 2015, p. 6). Moreover, a single indicator of common assaults was used for all assaults, including assaults with a weapon or aggravated assaults, and this is a limitation because although they occur less frequently, serious assaults are more costly to society (see Gabor, 2016). As a result, while showing a substantial cost savings, these results must be interpreted carefully, as factors unrelated the CMPA might be responsible for these outcomes. Considering both the direct and indirect costs of crime is useful, however, in helping policymakers better understand the true costs of crime.

\section{DISCUSSION}

Our analyses reveal that the introduction of the CMPA is associated with a reduction in property and violent crimes, and we also find support for a decrease in the direct and indirect costs of crime to society. Even though the crime reduction was modest, it provides a significant cost savings to society. The results in Table IV indicate a total cost reduction of either $\$ 150,104$ or $\$ 397,178$ per month if the February 1, 2011 to July 31, 2011 cases were excluded, which show the influence of the time frame being examined, and the cost estimates used in the analyses. Altogether, that results in a cost savings for the 47
TABLE III Prince Albert crime rates, pre- and post-CMPA implementation, January 1, 2006 to June 30, 2015

\begin{tabular}{lcccc}
\hline & Months & Mean & SD & p value \\
\hline Crime & & & & \\
$\quad$ Violent & 106 & 200.48 & 44.33 & --- \\
$\quad$ Property & 106 & 635.79 & 164.87 & --- \\
$\quad$ Other & 106 & 521.71 & 89.36 & --- \\
$\begin{array}{l}\text { Pre-implementation } \\
\text { 09/2006 to 01/2011 }\end{array}$ & & & & \\
$\quad$ Violent & 53 & 213.32 & 39.62 & --- \\
$\quad$ Property & 53 & 676.23 & 166.82 & --- \\
$\quad$ Other & 53 & 513.21 & 91.67 & ---
\end{tabular}

Post-implementation $07 / 2010$ to $06 / 2015$

$\begin{array}{lllcc}\text { Violent } & 53 & 187.64 & 45.41 & .002^{a} \\ \text { Property } & 53 & 595.34 & 154.02 & .011^{a} \\ \text { Other } & 53 & 530.22 & 87.02 & .330\end{array}$

Pre-implementation 09/2006 to $01 / 2011$

$\begin{array}{llccc}\text { Violent } & 53 & 213.32 & 39.62 & --- \\ \text { Property } & 53 & 676.232 & 166.82 & --- \\ \text { Other } & 53 & 513.21 & 91.67 & --\end{array}$

Post-implementation $02 / 2011$ to $06 / 2015$

(Excludes 02/2011 to 07/2011)

\begin{tabular}{lllll} 
Violent & 47 & 180.00 & 40.80 & $.000^{a}$ \\
Property & 47 & 584.49 & 151.28 & $.005^{a}$ \\
Other & 47 & 531.87 & 90.30 & .309 \\
\hline
\end{tabular}

a $p \leq .05$

months that would range from $\$ 7$ to $\$ 18.7$ million to society after CMPA was founded in 2011 to mid-year 2015. While that range is admittedly quite broad, those cost outcomes were somewhat dependent upon the prevalence of crimes, such as assaults that occur often, where the cost estimates for that category of offences are quite divergent $(\$ 19,075$ and $\$ 58,886$, respectively). By taking a conservative approach and focusing our estimates at the midpoint of those two values, we find that the total savings to society would be $\$ 12.85$ million from February 2011 to June 30, 2015.

Although our findings show that the Hub model is a promising crime control strategy, there are a number of caveats that need to be considered. First, our research design makes it impossible to attribute the crime and subsequent cost savings to the CMPA alone, as other law enforcement or justice system interventions might be responsible for some of these changes. Moreover, other factors unrelated to the justice system, such as improving economic conditions, might moderate crime more effectively at the civic level than the activities of the police, courts, or corrections. In addition, serious offences, such as homicides, might be sensitive to a number of factors apart from the influence of the CMPA. The delivery of prompt emergency medical care, for example, might make the difference between a homicide 
PRINCE ALBERT'S CRIME/RISK REDUCTION APPROACH, Sawatsky et al.

TABLE IV Cost differences pre- and post-implementation; all crime occurrences, Jan 1, 2006 to June 30, 2015

\begin{tabular}{|c|c|c|c|c|c|c|c|}
\hline $\begin{array}{l}\text { Offence: Occurrences } \\
\text { pre-post hub } \\
\text { implementation } \\
\text { (106 Months) }\end{array}$ & $\begin{array}{l}\text { Pre hub } \\
\text { (mean) }\end{array}$ & $\begin{array}{l}\text { Post hub } \\
\text { (mean) }\end{array}$ & Difference & $\begin{array}{l}\text { Mean cost per } \\
\text { offence } \\
\text { (Gabor, 2016) }\end{array}$ & $\begin{array}{l}\text { Monthly } \\
\text { cost } \\
\text { savings }\end{array}$ & $\begin{array}{l}\text { Median cost per offence } \\
\text { (Gabor, 2016) }\end{array}$ & $\begin{array}{l}\text { Monthly } \\
\text { cost savings }\end{array}$ \\
\hline Murder & .23 & .25 & -.02 & $4,837,018$ & $-96,740$ & $5,400,708$ & $-108,014$ \\
\hline Sexual Assault & 7.40 & 8.42 & -1.02 & 136,372 & $-139,099$ & 139,347 & $-142,134$ \\
\hline Robbery & 7.87 & 7.13 & .74 & 32,002 & 23,681 & 28,056 & 20,761 \\
\hline Assault & 53.32 & 48.83 & 4.49 & 58,886 & 264,398 & 19,075 & 85,647 \\
\hline Break and Enter & 39.15 & 40.96 & -1.81 & 5,928 & $-10,730$ & 6,054 & $-10,958$ \\
\hline Vehicle Theft & 18.85 & 18.02 & .83 & 8,157 & 6,770 & 8,644 & 7,175 \\
\hline Fraud & 8.51 & 8.72 & -.21 & 45,030 & $-9,456$ & 45,030 & $-9,456$ \\
\hline TOTAL & & & & & 38,824 & & $-156,979$ \\
\hline
\end{tabular}

\begin{tabular}{lccccccc}
\hline $\begin{array}{c}\text { Offence: Occurrences } \\
\text { pre-post hub } \\
\text { implementation } \\
\text { (Excludes six months } \\
\text { 02/2011 to 07/2011) }\end{array}$ & $\begin{array}{c}\text { Pre hub } \\
\text { (mean) }\end{array}$ & $\begin{array}{c}\text { Post hub } \\
\text { (mean) }\end{array}$ & Difference & $\begin{array}{c}\text { Mean cost per } \\
\text { offence } \\
\text { (Gabor, 2016) }\end{array}$ & $\begin{array}{c}\text { Monthly } \\
\text { cost } \\
\text { savings }\end{array}$ & $\begin{array}{c}\text { Median cost per offence } \\
\text { (Gabor, 2016) }\end{array}$ & $\begin{array}{c}\text { Monthly } \\
\text { savings }\end{array}$ \\
\hline Murder & .23 & .21 & .02 & $4,837,018$ & 96,740 & $5,400,708$ & 108,014 \\
Sexual Assault & 7.40 & 7.94 & -.55 & 136,372 & $-75,005$ & 139,347 & $-76,641$ \\
Robbery & 7.87 & 7.19 & .68 & 32,002 & 21,761 & 28,056 & 19,078 \\
Assault & 53.32 & 46.94 & 6.38 & 58,886 & 375,693 & 19,075 & 121,699 \\
Break and Enter & 39.15 & 41.70 & -2.55 & 5,928 & $-15,116$ & 6,054 & $-15,438$ \\
Motor Vehicle Theft & 18.85 & 18.26 & .59 & 8,157 & 4,813 & 8,644 & 5,100 \\
Fraud & 8.51 & 8.77 & -.26 & 45,030 & $-11,708$ & 45,030 \\
\hline TOTAL & & & & & 397,178 & & $-11,708$ \\
\hline
\end{tabular}

that costs society $\$ 5.4$ million and an aggravated assault offence, which costs society a fraction of that amount (Gabor estimated that the median cost of an aggravated assault as $\$ 113,573)$. Furthermore, with respect to the cost analysis, a complete accounting of the crime control benefits of the CMPA could not be undertaken as data were only available for seven types of crimes. As a result, offences such as wilful damage and other public order crimes that occur very often were not considered in the analysis. Despite that limitation, the efforts of the CMPA still resulted in a substantial cost savings to society.

The crime and cost reduction is especially noteworthy given that two-fifths (40\%) of PA arrestees are out-of-towners, and as a result, the Hub interventions with at-risk Prince Albert residents will have little influence on their conduct. As a gateway city, out-of-towners will continue to pass through PA and contribute to anti-social behaviour and crime, and it is difficult to develop any sort of meaningful intervention with this population as they may have very little stake in the host community's functioning. The results in Table I show that many of these visitors come from communities with very high rates of crime severity. Consequently, scholars evaluating the effectiveness of the Hub as a crime control strategy must take this fact into account, and a first step for these researchers is to determine the true contribution of out-of-towners on PA crime rates.
Implications for Further Research and Theory

The current research examined only two outcomes of the CMPA, which were the impact on police calls for service and police recorded crime, and the cost savings that resulted from those changes. While there are limitations with both of those measures, the results show that the CMPA approach is promising. Consequently, this intervention provides fertile ground for further research and study. As noted by Nilson (2015), a number of challenges are evident, that once overcome, have the likelihood to enhance service delivery by CMPA and improve outcomes for its clients. Once all agencies have put measures into place to show the efficiencies and effectiveness of this approach, a more comprehensive longitudinal study would determine the sustainability of this approach to community safety.

The literature reveals how two theoretical propositions are associated with the community mobilization model: social disorganization and crime prevention through social development. Both of these approaches outline how the social conditions within a community can contribute to reducing crime and social disorder. The approach taken by CMPA is intended to strengthen a community's ability to better regulate behaviour through developing more effective informal social controls. One of the favourable outcomes identified in this research was the reduction in social disorder occurrences that came to the attention of the police. As risk situations 
affecting individuals and families are reduced, stability will follow and an increase in collective efficacy will occur. Further research by scholars examining the outcomes of CMPA through the lenses of social disorganization, crime prevention through social development, collective efficacy, and into the direct impacts on lives from the perspective of clients served (Nilson, 2016), could prove fruitful in terms of contributing to theoretical development.

\section{CONCLUSIONS}

Analysis of crime data from 2006 to 2015 suggests that the CMPA was effective in reducing crime and lowering the costs to society for crime in Prince Albert. Reducing crime and disorder may also lower levels of social disorganization, which in turn might increase levels of informal social control. Higher levels of informal social control may further reduce crime and increase individual, family, and community well-being. The implementation of CMPA required the community, its social agencies, and police to come together to implement a new and innovative approach to crime reduction. It has attracted significant interest from other communities wishing to reduce crime and has also attracted the interest of the academic research community (McFee \& Taylor, 2014). This approach has the potential for improved crime reduction as it evolves through self-examination and by carrying out evaluations and other independent examinations by stakeholders and the academic community. Taylor (2016) reports by mid-year 2016, 77 sites had established interventions based on a Hub approach, although there is some variation in the manner in which these services are delivered in the different sites (Bhayani \& Thompson, 2016).

While the community of Prince Albert continues to face high crime rates and the issues of social disorganization caused by a highly transient and diverse population, the manner in which the community service agencies, police, academia, and political leadership have cooperated in the formation of the CMPA is commendable. Continued funding and support by each of the partner agencies is essential to the future success of this innovative model. Altogether, this research shows that this innovative community-based crime reduction strategy has shown promising results.

The appeal of the Hub approach is that, by prioritizing interventions with individuals and families with acutely elevated risk, the partnership agencies seek to support individuals and families in their efforts to build healthier lives, which in turn has a key role in reducing crime. This study demonstrates that the police-led partnership in PA has reduced crime, resulting in a cost savings to society.

Perhaps more importantly, the CMPA demonstrates that police-led crime control strategies can play a role in crime prevention. There is a growing body of scholarship highlighting that police services must shift their emphasis to less reactive and more proactive enforcement strategies (Braga \& Apel, 2016; Nagin, Solow, \& Lum, 2015). Policing has been described as an industry in search of a new key goal or overriding principle (Crank, Kadleck, \& Koski, 2010). Risk reduction strategies represent a significant step forward from the focus of traditional police responses based on offences that have already occurred. The findings reported above suggest the police-led strategies involving community agencies can reduce crime. A question that Crank, Kadleck, and
Koski (2010) ask, however, is whether the police are ready for such changes?

\section{ACKNOWLEDGMENTS}

This paper is an adaptation of a thesis entitled Prince Albert's Crime/ Risk Reduction Approach to Community Safety written by Murray J. Sawatsky in partial fulfillment of the requirements for the degree of Master of Arts in Police Studies at the University of Regina. Rick Ruddell and Nicholas Jones served as the author's thesis supervisor and committee member. Together, they collaborated to produce this adaptation for publication in the Journal of CSWB.

\section{CONFLICT OF INTEREST DISCLOSURES}

The authors state that there are no conflicts of interest.

\section{AUTHOR AFFILIATIONS}

*Department of Justice Studies, University of Regina, Regina, SK, Canada.

\section{REFERENCES}

Allen, M., \& Perreault, S. (2015). Police-reported crime in Canada's provincial North and territories, 2013. Ottawa, ON: Centre for Justice Statistics.

Andresen, M. A. (2012). Unemployment and crime: A neighborhood level panel data approach. Social Science Research, 41:1615-1628.

Aos, S., \& Drake, E. (2013). Prison, police and programs: Evidence based options that reduce crime and save money. Olympia, WA: Washington State Institute for Public Policy.

Bhayani, G., \& Thompson, S. K. (2016). SMART on social problems: Lessons learned from a Canadian risk-based collaborative intervention model. Policing. Published online ahead of print: doi:10.1093/police/paw040

Bottoms, A. E. (2006). Crime prevention for youth at risk: Some theoretical considerations. Resource Material Series, 68:21-34.

Braga, A., \& Apel, R. (2016). And we wonder why criminology is sometimes considered irrelevant in real world policy conversations. Criminology \& Public Policy, 15:813-829

Choi, K. S., Librett, M., \& Collins, T. J. (2014). An empirical evaluation: gunsho detection system and its effectiveness on police practices. Police Practice and Research, 15:48-61.

Community Mobilization Prince Albert. (2012).Report on the hub discussion 2011/2012. Prince Albert, SK: Author.

Crank, J. P., Kadleck, C., \& Koski, C. M. (2010). The USA: the next big thing Police Practice and Research, 11:405-422.

Day, D. M., Koegl, C. J., Rossman, L., \& Oziel, S. (2015). The monetary cost of criminal trajectories for an Ontario sample of offenders. Ottawa, ON: Public Safety Canada.

Dominguez, P., \& Raphael, S. (2015). The role of cost-of-crime literature in bridging the gap between social science research and policy making. Criminology \& Public Policy, 14:589-632.

Easton, S., Furness, H., \& Brantingham, P. (2014). The cost of crime in Canada Vancouver, BC: Fraser Institute.

eHealth Saskatchewan. (2015). Covered population 2015. Retrieved from: https://www.ehealthsask.ca/health-data/covered-population/ Documents/2015-covered-population.pdf

EKOS Limited. (2011). Govanhill operational hub - evaluation. Final report for Glasgow City Council. Glasgow, Scotland: Author.

Fenno, J. G. (2013). An examination of youth alcohol and drug use in Prince Albert. (Master of Arts thesis). University of Regina, Regina, SK.

Fenno, J. G. (2016). Prince Albert youth drug and alcohol use: a comparison study of Prince Albert, Saskatchewan, and Canada youth. Journal of Community Safety \& Well-Being, 1:61-65.

Gabor, T. (2016). Costs of crime and criminal justice responses. Ottawa, ON Public Safety Canada. 
Griffiths, C. T., Dandurand, Y., \& Murdoch, D. (2007). The social reintegration of offenders and crime prevention. Ottawa, ON: National Crime Prevention Centre.

Ha, O. K., \& Andresen, M. A. (2017). Unemployment and the specialization of criminal activity: A neighborhood analyses. Journal of Criminal Justice, 48:1-8.

Hamilton, C. (2016 September 16). A first world country with third world rates: Saskatchewan at the epicentre of HIV in Canada. National Post. Retrieved from http://news.nationalpost.com/news/canada/a-first-world-countrywith-third-world-rates-saskatchewan-at-the-epicentre-of-hiv-in-canada

Heaton, P. (2010). Hidden in plain sight: What cost-of-crime research can tell us about investing in police. Santa Monica, CA: RAND Corporation.

Jamieson, W. (2008). Factors related to successful mobilization of communities for crime prevention. IPC Review, 2:11-33.

Jennings, W. G., Lynch, M. D., \& Fridell, L. A. (2015). Evaluating the impact of police officer body-worn cameras (BWCs) on response-to-resistance and serious external complaints: Evidence from the Orlando police departmen (OPD) experience utilizing a randomized controlled experiment. Journal of Criminal Justice, 43:480-486.

Lee, S., Aos, S., \& Pennucci, A. (2015). What works and what does not? Benefit-cost findings from WSIPP. Olympia, WA: Washington State Institute for Public Policy.

Leo, G. (2015 June 8). HIV cases in Prince Albert 3.5 times the national average. CBC News Saskatchewan. Retrieved from http://www.cbc.ca/ news/canada/saskatchewan/hiv-cases-in-prince-albert-3-5-times-thenational-rate-1.3097590

Lum, C., Koper, C. S, \& Telep. C. (2011). The evidence-based policing matrix. Journal of Experimental Criminology, 7:3-26.

Maxwell, A. (2015). Adult criminal court statistics in Canada, 2013/2014. Ottawa, ON: Canadian Centre for Justice Statistics.

McCluskey, K. (2013 February 3). Proceed until apprehended. 2013-14 Dr. Gordon Wicijowski Law Foundation of Saskatchewan in Police Studies Lecture. Regina, SK.

McCollister, K. E., French, M. T., \& Fang, H. (2010). The cost of crime to society: New crime-specific estimates for policy and program evaluation. Drug and Alcohol Dependence, 108:98-109.

McFee, D. R., \& Taylor, N. E. (2014). The Prince Albert Hub and the emergence of collaborative risk-driven community safety. Ottawa, ON: Canadian Police College Discussion Paper Series.

Nagin, D., Solow, R. M., \& Lum, C. (2015). Deterrence, criminal opportunities, and the police. Criminology, 53:74-100.

Nilson, C. (2014). Risk-driven collaborative intervention. A preliminary impact assessment of community mobilization Prince Albert's HUB model. Saskatoon, SK: University of Saskatchewan, Centre for Behavioural Science and Justice Studies.
Nilson, C. (2015). The original game changers: An evaluative report on Prince Albert's Centre of Responsibility and its role in the advancemen of community mobilization efforts to improve community safety and wellness. Saskatoon, SK: Centre for Forensic Behavioural Science and Justice Studies.

Nilson, C. (2016). Canada's hub model: Calling for perceptions and feedback from those clients at the focus of collaborative risk-driven intervention. Journal of Community Safety \& Well Being, 1:58-60.

Perreault, S. (2015). Criminal victimization in Canada, 2014. Ottawa, ON: Canadian Centre for Justice Statistics.

Pilon, R. (2015 May 4). Snow melt reveals thousands of dirty needles in Prince Albert. CBC News Saskatchewan. Retrieved from: http://www.cbc. $\mathrm{ca} /$ news/canada/saskatchewan/snow-melt-reveals-thousands-of-dirtyneedles-in-prince-albert-1.3058338

Sawatsky, M. (2016). Prince Albert's crime/risk reduction approach to community safety. (Unpublished Master of Arts thesis). Regina, SK: University of Regina.

Skogan, W. G. (2012). Disorder and crime in B. C. Welch \& D. P. Farrington (eds). The Oxford handbook of crime prevention (Chapter 9). New York: Oxford University Press.

Statistics Canada. (2009). Measuring crime in Canada: Introducing the crime severity index and improvements to the uniform crime reporting survey. Ottawa, ON: Author.

Statistics Canada. (2016). Crime severity index and weighted clearance rates, by police service, Saskatchewan. CANSIM table 252-0087. Ottawa, ON: Author.

Taylor, N. E. (2010). A province-wide policing strategy to reduce crime, build safe communities and secure the future for Saskatchewan. Ottawa, ON: Author.

Taylor, N. E. (2016, Sept. 29). Quick outcome data on the Hub model [information presented at a public forum]. Presented at the Standing Senate Committee on Legal and Constitutional Affairs. Saskatoon, SK.

Tonry, M. (2015). The fog around cost-of-crime studies may finally be clearing Criminology and Public Policy, 14:653-671.

United Nations Office on Drugs and Crime. (2010). Handbook on the crime prevention guidelines: Making them work. New York, NY: Author.

Welch, B. C., \& Farrington, D. P. (2010). The future of crime prevention: Developmental and situational strategies. Prepared for National Institute of Justice. Rockville, MD: National Institute of Justice.

Zhang, T. (2011). Costs of crime in Canada, 2008. Ottawa, ON: Department of Justice Canada.

Zhang, T., Hoddenbagh, J., McDonald, S., \& Scrim, K. (2013). An estimation of the economic impact of spousal violence in Canada, 2009. Ottawa ON: Department of Justice Canada. 